\title{
Spousal care-giving arrangements in Europe. The role of gender, socio-economic status and the welfare state
}

\author{
Ariane Bertogg* and Susanne Strauss \\ Department of History and Sociology, University of Konstanz, Konstanz, Germany \\ ${ }^{*}$ Corresponding author. Email: ariane.bertogg@uni-konstanz.de
}

(Accepted 30 August 2018; first published online 8 October 2018)

\begin{abstract}
Spouses (and partners) are the most important source of care in old age. Informal care for frail spouses is provided by both sexes and across all socio-economic backgrounds and welfare policy contexts. There are, however, interesting differences as to whether spouses care alone, receive informal support from other family members or formal support from professional helpers, or outsource the care of their spouse completely. The present article contributes to the literature by differentiating between solo spousal care-giving and shared or outsourced care-giving arrangements, as well as between formal and informal care support. Moreover, we show how care-giving arrangements vary with gender, socio-economic status and welfare policy. Adding to previous research, we compare 17 countries and their expenditures on two elder-care schemes: Cash-for-Care and Care-in-Kind. The empirical analyses draw on the most recent wave of the Survey of Health, Ageing and Retirement in Europe (SHARE) data from 2015. Our results show that men have a higher propensity to share care-giving than women, albeit only with informal supporters. As expected, welfare policy plays a role insofar as higher expenditure on Cash-for-Care schemes encourage informally outsourced care-giving arrangements, whereas Care-in-Kind reduce the likelihood for informally shared or outsourced care-giving arrangements. Moreover, the influence of these welfare policy measures differs between individuals of different socio-economic status but not between men and women.
\end{abstract}

Keywords: spousal care-giving; informal care; gender; social class; welfare policy; Europe

\section{Introduction}

Against the backdrop of increasing longevity (Eurostat, 2017), the inquiry into the causes of and motivations for informal care also has grown in importance. Spouses and partners are an important source of care and often act as 'primary care-givers'. Even though many care-related tasks are still female-dominated, men are substantially engaged in spousal care-giving (Bond et al., 1999; Hirst, 2001; Ribeiro and Paul, 2008). Moreover, men's share of the informal care-giver volume is projected to increase further (Pickard et al., 2007). However, there are marked differences 
between countries regarding the amount and intensity of informal care provided to kin as well as gender and social equality in the division of such care work.

Welfare states, through financing and support schemes, have an impact on the care load encountered by informal care-givers of frail elderly people (Bettio and Plantenga, 2004). Specific policy measures and care infrastructure also have an impact on whether, how and with whom elder-care is shared. Additionally, care-related policies may even contribute to a consolidation and reproduction of gender and social inequalities as a result of long-term care-giving engagement (Schmid et al., 2012; Frericks et al., 2014). This may happen if 'classic' family forms (e.g. marriage or the breadwinner/home-maker model) are legally favoured, e.g. through tax regulations, or if informal care-givers receive no or low compensation for their work and face incomplete social protection. In such contexts, family care-giving is particularly attractive for individuals in part-time or low-income employment. This reinforces income, pension and social insurance gaps, and ultimately contributes to sustaining or increasing inequalities in older age (Frericks et al., 2014).

Despite the importance of the topic, there are only a small number of articles investigating older men's contribution to spousal care-giving based on representative data, and there are still several research gaps. The first relevant gap in the literature pertains to how care is measured. There is a body of older literature addressing gender differences in spousal care-giving (Arber and Ginn, 1994; Mutchler and Bullers, 1994), as well as a number of newer studies contrasting various care-giving arrangements (Feld et al., 2010; Suanet et al., 2012). However, these studies do not all distinguish between 'help' or support with instrumental activities of daily living (IADLs), such as cooking, shopping or cleaning, and 'care' or support with activities of daily living (ADLs), such as washing, feeding or dressing. ADL care receivers typically also require help with IADL, but not the other way around (Walker et al., 1995). Moreover, the boundaries between sharing household chores and IADL help are blurred and may be perceived and defined differently according to gender, the relationship with the care receiver and living arrangements (Dwyer and Seccombe, 1991; Arber and Ginn, 1994; Walker et al., 1995; Russell, 2007). After retirement or other major life changes, couples might adjust the division of household tasks without reporting it explicitly as care-giving. To avoid such definitory problems, and since we are interested in male involvement in the 'heavy', or physical, part of care work, the present article concentrates exclusively on ADL care-giving.

Second, we cannot rule out that there is more than one person involved in the home-based care of a frail elderly person. Spouses, children and home care services might share the care-giving tasks, with everyone doing what he or she can do best, thereby enabling dependent individuals to remain in their own home as long as possible. The choice of such shared care-giving arrangements is gender-specific: husbands are more likely to share care-giving with an informal helper, while wives are more likely to act as solo care-givers (Feld et al., 2010). The findings of Feld et al. (2010) contribute greatly to understanding the care-giving strategies and arrangements chosen by male and female spousal care-givers. To validate whether we can generalise these findings, however, they need to be replicated in a comparative manner, which is one of the aims of the present article. 
Finally, male care-giving has hardly ever been addressed with respect to welfare policy as a driver of or barrier to male engagement in spousal care-giving. One of the questions that has been discussed in the literature on care and welfare policy is whether formal care services replace family care-giving and thereby 'crowd out' family engagement, or whether family and formal services complement each other (Motel-Klingebiel et al., 2005). Empirical findings point out that formal and informal care-giving sources in Europe tend to complement rather than substitute for each other (Suanet et al., 2012; Balia and Brau, 2014). However, the opportunities to receive public care services are often limited time- and budgetwise, and additional care needs to be either privately financed or informally provided. Accordingly, the use of informal versus formal care or care support may not only differ between welfare states but may also vary with socio-economic status (Blomgren et al., 2011).

The present article thus aims at closing the aforementioned research gaps by investigating the involvement of men and women in spousal and partner ${ }^{1}$ care, as well as its link to socio-economic status and welfare policy. We investigate the circumstances under which men and women act as solo care-givers, decide to share their responsibilities, or outsource them to informal care-givers such as family members or a professional home care service. Moreover, we address the role that socio-economic status and welfare policy play in the choice of care-giving arrangements. In this respect, we investigate how involvement in spousal care-giving varies depending both on the households' socio-economic status as well as welfare state expenditures on two different elder-care schemes. The remainder of this article is structured as follows: the theoretical section discusses gender, socio-economic status and welfare policy as drivers of or barriers to spousal care-giving; then data and methods used in this study are described; the following section features the descriptive and multivariate analyses; and the article concludes with a discussion.

\section{Theoretical background}

Previous literature has reported substantial differences in the extent and intensity of elder, and thus also spousal, care-giving between women and men as well as between individuals from higher or lower socio-economic groups. These differences can be explained with two theoretical arguments which will be addressed in the following: gender role socialisation and economic considerations.

\section{Gender socialisation and care-giving}

Women, particularly from earlier birth cohorts, have been socialised to fulfil nurturing roles, deriving a part of their identity and social integration from caring. For women, caring for their dependent husbands has often been described as a continuation of earlier care-giving tasks (e.g. child-rearing). Starting to care for a frail spouse should, thus, require fewer adaptations for women than for men who newly transition into a 'career' of care-giving and eventually also housekeeping (Russell, 2007). Men have more legitimate 'excuses', such as lacking skills and routine, if they do not wish to take over personal care (Connidis and McMullin, 2002; Henz, 2010). We could thus expect that men are involved in spousal care-giving less 
often than women. This is also reflected in the literature on adult children's caregiving to their parents (Brandt et al., 2009; Henz, 2009).

On the other hand, spousal care can be described as 'care by default', arising from lifelong co-habitation and a close emotional bond (Arber and Ginn, 1994). Men, too, might choose deliberately to care for their sick spouses as they might otherwise 'lose' their lifelong companion. Caring for a sick or frail spouse is often seen as an extension of the love and support that has been exchanged for many years (Arber and Ginn, 1994; Corden and Hirst, 2011; Hong and Coogle, 2016). Caring for one's frail spouse is often culturally framed as a spousal duty. Moreover, spouses possess valuable knowledge about the frail elderly person's medical history, preferences and health behaviour, which facilitates care-giving. Gender might thus not only be an important factor when it comes to an individual's propensity to provide care for a spouse, but also with respect to the choice of caregiving arrangement. For instance, female care-givers spend on average more hours on care-giving than male care-givers (Noël-Miller, 2011), who do so often as secondary care-giver or support to the female main care-giver (Gerstel and Gallagher, 2001; Henz, 2009). An important question which was addressed by Feld et al. (2010) is to what extent care given to a spouse is performed alone ('solo care-giving'), or with either informal or formal support ('shared care-giving'). The authors found that men are less likely than women to be the sole care-givers, but more likely than women to share care-giving tasks. The distinction between solo and shared care seems thus an especially important aspect when describing male care-giving, as men have been shown to more readily accept help with caring tasks (Mutchler and Bullers, 1994; Bond et al., 1999; Henz, 2009). Moreover, men have been described as embracing a more delegating or 'managerial' approach to organising care (Deufert, 2013; Gallo and Scrinzi, 2016). We thus expect men to exhibit a higher likelihood of both outsourcing and sharing the care of their spouses, while women are expected to be more likely to act as solo care-givers.

- Hypothesis 1: Men are less likely than women to act as solo spousal caregivers.

\section{Economic explanations for care-giving}

Besides gender role socialisation, economic considerations are involved in an individual's decision regarding the choice of a care-giving arrangement. The household economy model (Becker, 1965) assumes that partners specialise by dividing paid and unpaid labour to maximise the household's utility and minimise costs. Men, and particularly male breadwinners, might encounter higher costs by reducing work hours or giving up employment to care for their spouse than by hiring a caregiver paid a lower salary than their own (Ettner, 1996). Economic considerations might also be at work when comparing the care-giving involvement of employed persons with persons who are not employed, or between income groups (Arber and Ginn, 1992; Sarkisian and Gerstel, 2004). Employed persons face higher opportunity costs, both time- and moneywise, and might thus be more likely to share or outsource care. The link between employment and elder-care is not free from issues of endogeneity. As previous research has shown, it is not the circumstance of care- 
giving, but rather the high intensity of the care, that leads to care-givers (gradually) dropping out of the labour market (Henz, 2009, 2010). This indicates that caregivers develop strategies to remain in the labour market. One of these strategies could be to outsource care completely, or to share it with a formal or informal source of support. As employees have a higher income than retired persons or individuals not in the labour market, they should also display a higher propensity to hire a formal care-giving service to supplement their care-giving responsibilities entirely. We can thus formulate two hypotheses:

- Hypothesis 2a: Employed persons are more likely to outsource care-giving to a third party than non-employed persons.

- Hypothesis 2b: Employed persons are more likely to share care-giving with a formal source of support than non-employed persons.

As pointed out earlier, since economic considerations are likely to play a role when deciding on a care-giving arrangement, solo and shared care-giving might not only vary depending on employment status, but also with respect to socio-economic status which entails greater financial resources such as income or home-ownership. Individuals with higher income might face considerably higher opportunity costs of engaging as (solo) care-givers than persons with lower income. They could thus be expected to be more likely to share or outsource care-giving. Moreover, the source of care support - formal services or informal helpers - with whom spousal care-giving is shared or to whom care is outsourced might vary, too, with socioeconomic status. Care receivers with a higher socio-economic status have been shown to be less dependent on informal care (Arber and Ginn, 1992; Blomgren et al., 2011), as they are more likely to be able to pay for formal care services.

In many European countries, even the publicly provided formal care partly needs to be paid 'out of pocket' by the care receiver or the number of care hours guaranteed are not sufficient for covering the care need. Since households with greater economic resources can rather afford to supplement the publicly provided care with their own means, households with fewer resources are more likely to rely (exclusively) on informal care-giving. We thus expect a higher propensity of informally shared or outsourced care-giving arrangements among individuals with lower socio-economic status, and a higher likelihood of sharing or outsourcing care-giving formally among persons with higher socio-economic status. Empirical evidence supports these two hypotheses. Informal family-based care-giving is often found among lower-income groups, while higher-income groups are more likely to choose formal home care (McAuley and Arling, 1984; Broese van Groenou et al., 2006). Besides income, home-ownership might play a role, too (Broese van Groenou et al., 2006; Corden and Hirst, 2011). Having no costs for rent frees up financial resources for hiring a paid care-giver, which should increase the likelihood of sharing care-giving formally. We can thus formulate two hypotheses:

- Hypothesis 3a: Persons with a higher socio-economic status (i.e. with higher income/home-owners) are more likely than persons with lower socioeconomic status to share or outsource care-giving with a formal service provider. 
- Hypothesis 3b: Persons with a lower socio-economic status (i.e. with lower income/not home-owners) are more likely than persons with higher socioeconomic status to share or outsource care-giving informally.

\section{Welfare states and family care}

Over the past two decades, elder-care has received increasing attention from welfare researchers (Pfau-Effinger, 2005; Saraceno and Keck, 2010; Suanet et al., 2012). As the baby-boomers approach old age, many countries face the challenge of providing care infrastructure for a growing number of frail elderly people. Over the past decade, expenditures for elder-care have risen in most countries (Eurostat, 2017), however their financing has remained a topic of public debate. There are four ways in which states can organise elder-care: first, by providing formal care in institutions; second, by providing publicly funded home care services (the so-called 'Care-in-Kind' services); third, by enabling family members or other private persons to act as informal care-givers for a frail person (through care-giver allowances, the so-called 'Cash-for-Care' schemes); and fourth, by obliging family members to take responsibility for the care of their kin (Pfau-Effinger, 2005).

However, these four ways constitute strictly ideal types. Most welfare states provide a mix of several strategies, whereby Cash-for-Care and Care-in-Kind have become the most important pillars. Cash allowances, by providing wages for informal care-givers, promote informal care-giving arrangements. They may, however, in some countries also be used to purchase services on a privatised market (Frericks et al., 2014). Care-in-Kind schemes rather promote formal care-giving. By providing formal services for ADL and IADL delivered to the home of the care recipient, they enable receivers to remain in their own homes as long as possible. For instance, in Southern and Eastern European countries, more informal care-giving occurs due to a lack of public care facilities. In Northern European countries and the Netherlands, on the other hand, where formal home care services are more developed, less informal and family care-giving is provided (Alber and Kohler, 2004).

Several approaches have been undertaken to formulate welfare state classifications based on the organisation of elder-care (Bettio and Plantenga, 2004; Haberkern and Szydlik, 2010; Saraceno and Keck, 2010). In their comparison of the explanatory power of these different typologies for elderly people's participation in informal care-giving, Strauss and Trommer (2017) yield support for the typology advanced by Saraceno and Keck (2010) who point out that defamilised welfare states generally reduce the care load for the family. As the overall burden of care work diminishes with higher expenditures on elder-care infrastructure, children's involvement in the physical care of their parents might be 'crowded out' (Brandt et al., 2009). For co-resident spouses, on the other hand, the availability of professional home care support might reduce the actual workload, but not the propensity of being involved in care-giving. This is in line with the study by Hank (2011), who concludes that the probability of helping and caring individuals rises with increasing social government spending.

Besides impacting on the choice of care-giving arrangement, different care policies also have the power to either increase or reduce gender inequalities in 
care-giving (Orloff, 1996; Bettio and Plantenga, 2004; Schmid et al., 2012). Generally, increasing female participation in the labour market is regarded as the key to reducing gender inequalities (Frericks et al., 2014). By promoting formal care arrangements, Care-in-Kind facilitates reconciling employment and caregiving, and enables both male and female spousal care-givers to remain in gainful employment. Higher expenditures on Care-in-Kind schemes could thus be expected to have the same impact on men's and women's choices of care-giving arrangements. On the other hand, Cash-for-Care schemes promote informal caregiving by paying so-called 'care-giver wages'. However, as these wages are rarely competitive with labour market incomes, they are particularly attractive for individuals employed part-time or earning only low wages (mostly women, see Frericks et al., 2014). Higher expenditures on Cash-for-Care schemes are thus likely to influence male and female engagement in spousal care-giving differently. With regard to shared and outsourced care as well as formal and informal care support, one would expect women to be particularly likely to act as solo spousal care-givers and men to be more likely to share or outsource care informally under Cash-for-Care schemes. This can be explained, respectively, with the financial incentives to remain in the labour market (for men) and to give up paid work (for female spousal care-givers as well as for potential female informal care-givers, e.g. daughters):

- Hypothesis 4: Higher expenditures on Care-in-Kind services do not lead to differences in the choice of care-giving arrangements between men and women. Cash-for-Care programmes promote solo care-giving for women and informally shared or informally outsourced care-giving for men.

Besides gendered impacts, welfare policies and their influence on care-giving arrangements can also be expected to vary with socio-economic status, as empirical research suggests. Comparing Finland and England, Blomgren et al. (2011) showed that in market-based care systems like England, children provide informal care when parents have a low socio-economic status and thus limited access to formal care services. In social-democratic Finland, by contrast, children are not only more likely to supplement formal care services than in England, they also do so irrespective of parents' socio-economic status as the receipt of formal care does not depend on financial resources. Based on data from four European countries, Broese van Groenou et al. (2006) showed that the use of informal and formal care has a social gradient. While frail elderly people with lower socio-economic status are more likely to receive informal family-based care, individuals with a higher socio-economic status are more likely to receive formal care. This strengthens the argument that, in contexts where formal care-giving is promoted, financial resources play a smaller role for the choice of care-giving arrangement whereas in contexts where informal care-giving is promoted, the opportunity to purchase formal care depends largely on one's own financial resources.

- Hypothesis 5: Higher expenditures for Care-in-Kind services do not lead to differences in the choice of care-giving arrangement between individuals with higher or lower socio-economic status. Cash-for-Care programmes increase the likelihood of individuals with low socio-economic status choosing 
an informally shared or informally outsourced care-giving arrangement and increase the likelihood of individuals with high socio-economic status choosing a formally shared or formally outsourced care-giving arrangement.

\section{Control variables}

Two theoretical models are frequently referred to in the literature on caring: the Andersen-Newman model (Andersen and Newman, 1973) and the task-specific model (Messeri et al., 1993). Both models address the choice of the 'optimal' caregiver from the perspective of the care receiver. Drawing on these models, we can identify a range of important need, enabling and predisposing factors to explain the choice of care-giving arrangement. Besides age, the number and severity of the care receiver's health limitations are the strongest predictors of a person's need for help (McAuley and Arling, 1984). Disability as well as mobility and ADL limitations have been found to determine the degree of care needed (Balia and Brau, 2014). On the other hand, the health of the care-giver plays a role, too (Corden and Hirst, 2011; Shen et al., 2015). Our models thus contain indicators on the functional health of both respondent and spouse. Moreover, we can assume that if both spouses are limited functionally, they are most likely to delegate care to a third party. We thus also include an interaction term between the respondent's and spouse's functional health limitations.

Whether and how the care of one's spouse is shared depends also on the availability and characteristics of informal helpers, particularly, the family network. Children, next to spouses, are the most important source of informal care-giving to the elderly. Several comparative studies have investigated children's care-giving to their elderly and needy parents. Daughters are more frequently involved in parental care-giving than sons. Moreover, the further away a child lives, the more unlikely he or she is to provide care for his or her parents (Brandt et al., 2009; Schmid et al., 2012). Men are particularly likely to share care-giving with informal helpers when there are daughters living nearby (Feld et al., 2010). In our models, we thus include information on the number of the care receiver's daughters (as in cases where the couple is re-married or re-partnered, information on the children of the care receiver is favourable) as well as on the number of children of the care receiver who live within a 25 kilometre radius (Suanet et al., 2012).

\section{Data and methods}

The present article draws on data of the sixth wave of the Survey of Health, Ageing and Retirement in Europe (SHARE) (Börsch-Supan, 2017). A total of 68,231 people from 17 countries were interviewed in 2015, with participants from Austria, Belgium, Croatia, Czech Republic, Estonia, Denmark, France, Germany, Greece, Italy, Luxembourg, Poland, Portugal, Slovenia, Spain, Sweden and Switzerland. The respondents aged at least 50 years, as well as their spouses or partners living in the same household, were interviewed via a computer-assisted personal interview. Our reference population are couples aged 50 years or older living together in their own home $(\mathrm{N}=63,561)$. For the multivariate analyses, we only include households where both partners took part in the survey, as we need information 
on the spouse's age and health as well as any care they have received from persons other than our respondents. This leaves us with 49,022 valid cases, of whom 4,012 are engaged in spousal care-giving or have a spouse who receives care from a third person. Our data-set was restricted to those participants and countries taking part in Wave 6, as it was only for the subjects interviewed in Wave 6 that we had sufficiently detailed information on formal and informal care receipt involving individuals both from within and outside the household (see below).

\section{Dependent variable}

Our analyses compare solo care-givers with men and women who share the care of their spouse or outsource it to a third person. To generate our dependent variable, we use three items. The first item assesses the respondent's spousal care-giving. It is phrased as follows: 'Is there someone living in this household who you have helped regularly during the last 12 months with personal care, such as washing, getting out of bed or dressing?', followed by a list of persons from which to choose the care receiver. The second and third items are taken from the spouse's interview. They assess whether the spouse has received help from a third person. They were worded as follows: 'Which (other) family member outside the household, friend or neighbour has helped you in the last 12 months?' for informal care receipt, and 'During the last 12 months did you receive any professional or paid help listed on this card due to a physical, mental, emotional or memory problem?' for formal care receipt. If answered with 'yes', both items were followed up with a specification of the type of help received (personal care, domestic help, help with paperwork), whereby we only respected the receipt of personal care. Since the sixth wave of SHARE was the only wave which collected each of these three items, our analyses rely on that wave exclusively.

If the respondent reported giving care to his or her spouse, but the care receiver did not report any further care by a third person, the case was coded as 'solo caregiving'. 'Informally shared care-giving' applies to respondents giving care and their spouse reporting additional care received from children, other relatives, friends or neighbours, i.e. informal sources of care support exclusively. 'Formally shared' caregiving arrangements pertain to cases where the respondent reports spousal caregiving and the spouse reports receiving any formal care (including cases where informal plus formal care support was received). Outsourcing pertains to all cases where the respondent does not report providing care, but the spouse reports receiving care from a third party. It was distinguished likewise between only informal care-givers ('outsourced, informally') and care-giving outsourced to professional services or paid helpers, including care-giving arrangements where formal and informal care-givers are involved ('outsourced, formally').

As our dependent variable features five unordered categories, we apply multinomial logistic models with country dummies, and robust standard errors clustered at the household level. ${ }^{2}$ Cross-sectional analyses often face problems of endogeneity. To check for the robustness of our results, we also calculate fixed-effects logistic regression models using SHARE Waves 1, 2, 4, 5 and 6, with a dummy variable (no/ yes) capturing the occurrence of spousal care-giving in the respective wave as a dependent variable (see Table 3 in the online supplementary material). Since the 
focus of our paper is, however, on the various care-giving arrangements of spousal care-givers, these models can only serve as additional information to address the question of endogeneity.

\section{Independent variables}

As independent variables, we use information both from the respondent as well as from the respondent's spouse living in the same household (for an overview, see Table 1 in the online supplementary material). Respondent characteristics included in the models are: gender, age (which must be 50 years or older), the number of functional limitations, which was calculated as the sum of the self-reported number of mobility limitations plus the self-reported number of ADL limitations (ranging from 0 to 15), as well as a dichotomous variable which takes on the value ' 1 ' if the respondent is employed or self-employed. To account for the socio-economic status of our subjects, we use a dummy variable for home-ownership, as well as countryspecific weighted quintiles on household income. The income quintiles were obtained using the imputed variable on the net household income, which was then weighted by the number of persons living in the household (where the first household member counted as a full person and every additional person counted as 0.5 , with households of more than seven members being treated as if they contained seven members). In a second step, we aggregated the thus weighted income variable by country into quintiles to place the respondents and their households according to their socio-economic status within their national contexts. For the interaction terms between socio-economic status and the two macro indicators, we created a dummy variable which takes on the value ' 1 ' if the respondent was placed in the lowest or second-lowest quintile of the thus generated income variable.

Information retrieved from the spouse includes the age of the spouse, the number of functional limitations (calculated the same way as for the respondent), the number of daughters, the number of children who are living within a 25 kilometre radius, as well as the receipt of practical help (i.e. household help but not care) from outside the household.

At the macro-level, we insert dummy variables for each country, with Germany taken as the reference category. For the models featuring macro indicators, we look at the relative size of government spending on Cash-for-Care and Care-in-Kind schemes as their share as a percentage of the Gross Domestic Product (Organisation for Economic Co-operation and Development, 2017). These macro indicators are lagged by one year prior to the year in which the SHARE Wave 6 survey took place. To check the robustness of the results, we also checked a range of further indicators, among others the percentage of employees in the social sector as an indicator for an extensive welfare state (see e.g. Haberkern and Szydlik, 2010; Hank, 2011). These findings are not displayed; however, the coefficients indicate robustness across the models. To account for gender-specific or socioeconomic status-specific impacts of welfare spending in care-giving arrangements, we calculate four separate models with cross-level interactions between the two macro indicators and gender and socio-economic status, respectively. 


\section{Findings}

\section{Descriptive findings}

Our dependent variable distinguishes between solo and shared care-giving arrangements, or care outsourced to a third care-giver. Moreover, we separate informal from formal care support. The focus lies on individuals who care for a spouse, or individuals living with their care-receiving spouse in the same household. We are interested in both gender-specific (see Figure 1) and country-specific differences in care-giving arrangements (see Figure 2). Women are more likely to act as solo care-givers, while men are both more prone to share care-giving and to outsource care-giving completely. These are bivariate findings, however, not controlling for age or actual health status, which is one of the main reasons behind women's higher involvement in spousal care (Feld et al., 2010).

Figure 2 displays country differences. Common to all countries is the high share of solo spousal care-giving, which depicts the most popular 'option' (the darkest bars on the left-hand side). In all but four countries, namely Luxembourg, Spain, Poland and Germany, more than half of the individuals who live together with a spouse who receives care provide that care themselves without any further support. An overall high share of care outsourced to a third person (light grey bars on the right-hand side) can be found in Portugal, Italy, Spain and Poland; whereas informal outsourcing (often to a family member) occurs more often in Mediterranean and Eastern European countries, formal outsourcing is comparatively likely to occur in Switzerland, Belgium, Luxembourg and Portugal. Informally shared care-giving (dark grey bars, second from left) is most prominent in Eastern European and Balkan countries, namely Poland, Slovenia, Estonia and the Czech Republic. Formally shared care-giving (medium grey bars, middle) is most common in Luxembourg and Germany, followed by France, Sweden and Belgium. Contradicting common assumptions about the 'Scandinavian welfare model', formally shared care-giving is relatively rare in Denmark and less common in Sweden than in Germany or Luxembourg. Again, these findings are of a bivariate nature and will be replicated in a multivariate model.

\section{Multivariate findings: individual-level factors}

In a second step, we thus compare solo care-givers to persons who share care, either with other informal helpers or a home care service, and persons who outsource care completely to a third (formal or informal) care-giver (see Table 1). To illustrate our main effects (for gender, socio-economic status, and the interaction between welfare policy and socio-economic status), we also present figures with average marginal effects below.

As expected (Hypothesis 1), men are less likely to act as solo care-givers than women (for average marginal effects, see Figure 3). Men are more likely than women to both outsource care-giving and to share care-giving. However, the latter is only true for informally shared care-giving, i.e. care-giving shared with one's children or other family members, friends or neighbours. With respect to the odds of choosing formally shared care-giving over solo care-giving, men and women do not differ. With respect to outsourcing the care of their dependent spouse to a third 


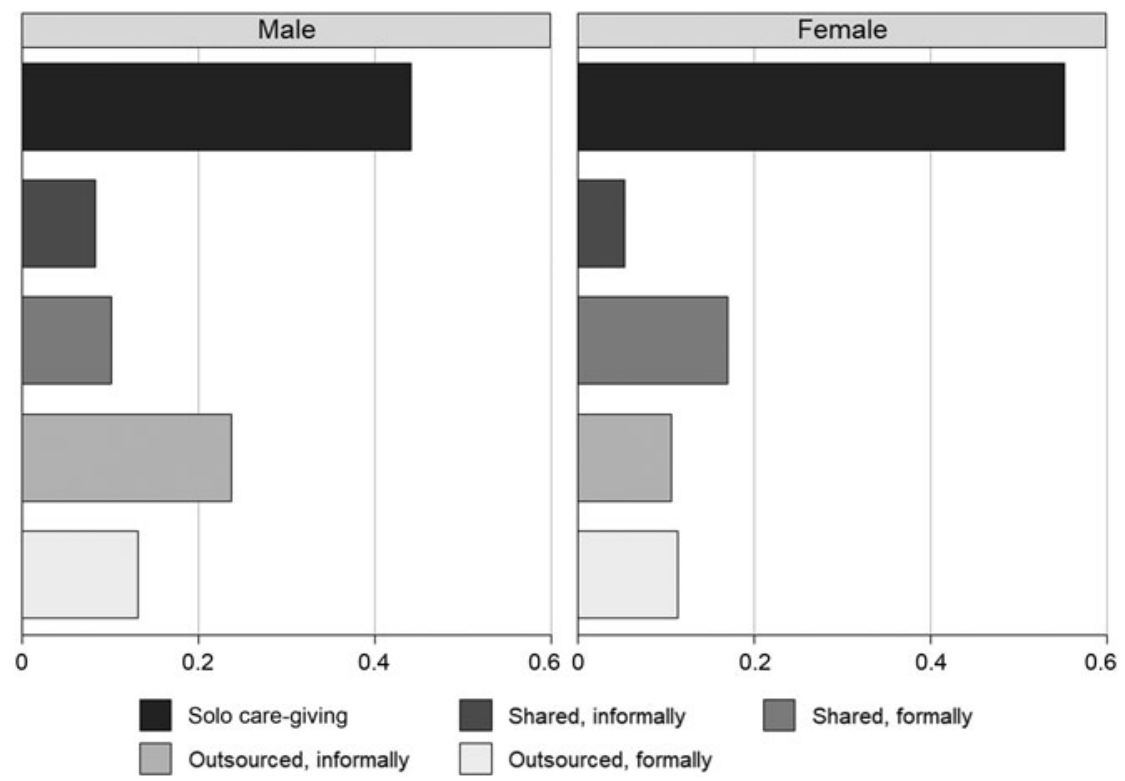

Figure 1. Female and male solo, shared and outsourced care-giving.

Notes: $\mathrm{N}=4,012$ respondents aged 50 years or older, living in a common household with partner or spouse who has also completed the interview.

Source: Survey of Health, Ageing and Retirement in Europe (SHARE) Release 6.0.0, Wave 6 (own calculations, weighted results).

party, men are more likely to choose both formally and informally outsourced caregiving arrangements than women. For the most part, the data primarily support our first hypothesis, as men are more likely to outsource the care of their frail spouses completely and to share care informally, albeit not formally.

Employed individuals are generally less likely to act as solo care-givers than individuals who are not employed. They have significantly greater odds of choosing informally shared care-giving over being the solo care-giver. Being employed is also positively associated with outsourcing, which is true for both types of outsourcing (formally and informally). These findings support Hypothesis 2a, insofar as being employed is positively associated with the likelihood of choosing informal care support, but not Hypothesis $2 \mathrm{~b}$, from which we would have expected employed care-givers to be more likely to choose formal care support. Employment entails both time restrictions and financial opportunity costs which might not only hinder solo care-giving but also influence the choice of care support. For employed persons whose spouse is in need for care, sharing care responsibilities with informal helpers might be chosen over sharing care with formal support, because informal helpers are more flexible at providing care-giving around one's work schedule. The current findings seem to suggest that the availability of time is a more important factor than opportunity costs when it comes to choosing care-giving arrangements.

Our third hypothesis addressed the role of socio-economic status, represented by country-specific income quintiles and home-ownership. With respect to income, 


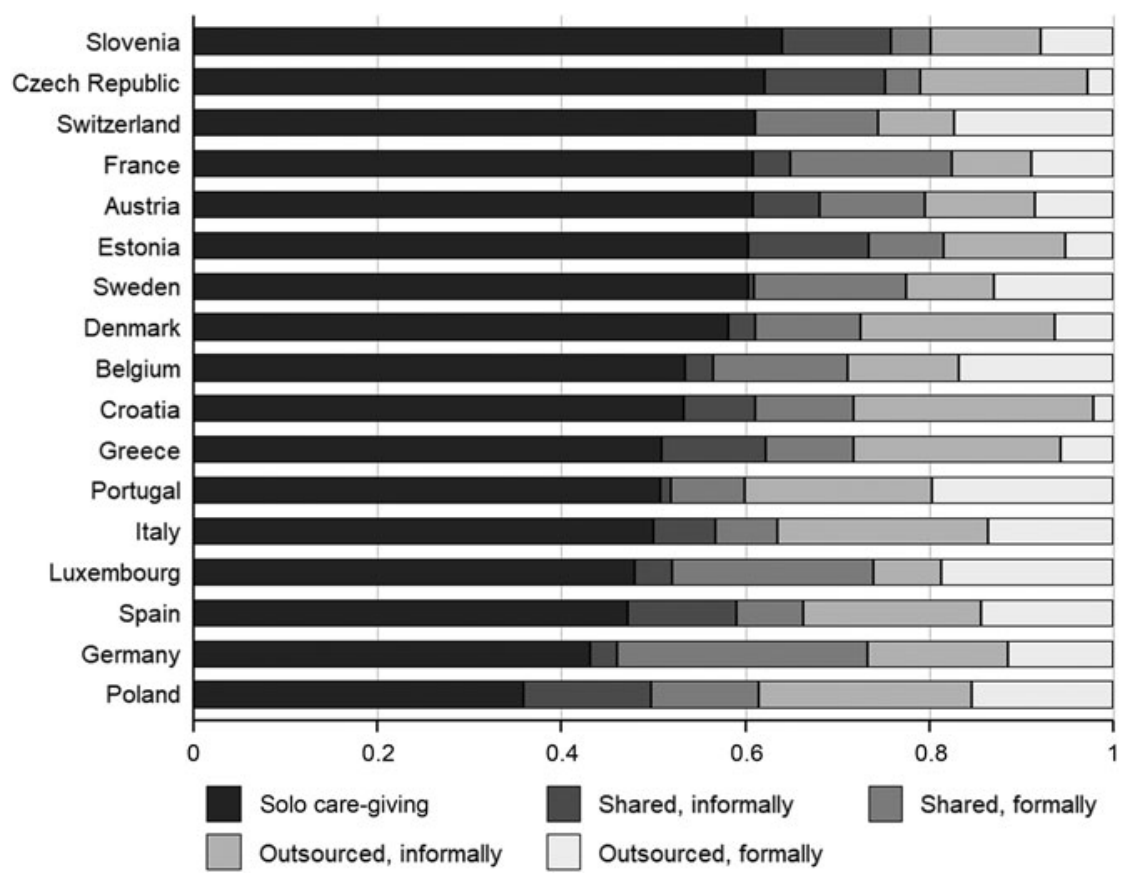

Figure 2. Solo, shared and outsourced care-giving by country.

Notes: $\mathrm{N}=4,012$ respondents aged 50 years or older, living in a common household with partner or spouse who has also completed the interview.

Source: Survey of Health, Ageing and Retirement in Europe (SHARE) Release 6.0.0, Wave 6 (own calculations, weighted results).

no clear picture emerges. Contrary to our expectations (Hypothesis 3a), higher income is not associated with a higher propensity to share or outsource care-giving formally, just as lower income is not significantly associated with a higher propensity to share care-giving informally. Further bivariate analyses (not shown) revealed that even without controlling for potential confounders, the expected association between income and choice of care support cannot be corroborated. One reason for this might be that income inequalities diminish after retirement age, as pensions are often subject to redistribution. A second reason might be that the effect of financial resources on choice of care-giving arrangement depends on the welfare policy context (see Broese van Groenou et al., 2006).

To check the consistency of this finding, we dichotomised the income variable with the bottom two quintiles taking on the value ' 1 ' in the newly created dummy variable. Figure 4 depicts the average marginal effects for the dichotomous income variable as well as the dummy variable pertaining to home-ownership. There is a noticeable tendency among people with higher earnings to care alone (left panel of Figure 4), as well as a significantly higher propensity towards informal outsourcing in the lower ranks of the respective national income distributions, which is in line with our hypothesis (Hypothesis 3b) and corresponds to the literature (Blomgren et al., 2011; Brandt et al., 2009). Our second indicator for 
Table 1. Solo versus shared versus outsourced care-giving

\begin{tabular}{|c|c|c|c|c|}
\hline Solo care-giving versus & $\begin{array}{l}\text { Shared, } \\
\text { informally }\end{array}$ & $\begin{array}{l}\text { Shared, } \\
\text { formally }\end{array}$ & $\begin{array}{l}\text { Outsourced, } \\
\text { informally }\end{array}$ & $\begin{array}{l}\text { Outsourced, } \\
\text { formally }\end{array}$ \\
\hline \multicolumn{5}{|c|}{ Respondent characteristics: } \\
\hline Male & $0.43^{\star}(0.18)$ & $-0.05(0.16)$ & $0.87^{\star \star \star}(0.18)$ & $0.20(0.15)$ \\
\hline Employed & $0.78^{\star \star}(0.28)$ & $0.43(0.28)$ & $1.05^{\star \star \star}(0.24)$ & $1.18^{\star \star \star}(0.31)$ \\
\hline \multicolumn{5}{|c|}{ Household income (Ref. Fifth quintile): } \\
\hline Fourth & $-0.09(0.28)$ & $0.06(0.23)$ & $0.00(0.23)$ & $0.32(0.27)$ \\
\hline Third & $-0.10(0.26)$ & $-0.33(0.23)$ & $0.15(0.22)$ & $0.10(0.27)$ \\
\hline Second & $0.08(0.27)$ & $-0.11(0.25)$ & $0.48^{\star}(0.24)$ & $0.40(0.27)$ \\
\hline First & $0.51(0.33)$ & $-0.01(0.26)$ & $1.05^{\star \star \star}(0.26)$ & $0.48(0.33)$ \\
\hline Home-ownership & $0.02(0.17)$ & $0.36^{\star}(0.15)$ & $0.14(0.15)$ & $-0.01(0.15)$ \\
\hline Age & $0.00(0.02)$ & $0.03(0.02)$ & $0.03(0.02)$ & $0.06^{\star \star \star}(0.01)$ \\
\hline $\begin{array}{l}\text { Number of functional } \\
\text { health limitations }\end{array}$ & $-0.04(0.05)$ & $-0.11^{\star \star}(0.04)$ & $-0.08^{\star \star}(0.03)$ & $-0.08^{\star}(0.03)$ \\
\hline \multicolumn{5}{|l|}{ Spouse characteristics: } \\
\hline Age & $0.02(0.02)$ & $0.03(0.02)$ & $-0.00(0.01)$ & $0.03^{\star}(0.01)$ \\
\hline $\begin{array}{l}\text { Number of functional } \\
\text { health limitations }\end{array}$ & $0.16^{\star \star \star}(0.02)$ & $0.17^{\star \star \star}(0.02)$ & $-0.08^{\star \star \star}(0.02)$ & $0.04(0.02)$ \\
\hline Number of daughters & $0.11(0.07)$ & $-0.10(0.07)$ & $0.27^{\star \star \star}(0.07)$ & $0.06(0.07)$ \\
\hline $\begin{array}{l}\text { Number of children } \\
\text { living nearby }\end{array}$ & $0.01(0.10)$ & $-0.15(0.11)$ & $0.03(0.08)$ & $0.06(0.10)$ \\
\hline $\begin{array}{l}\text { Practical help from } \\
\text { outside household }\end{array}$ & $2.21^{\star \star \star}(0.22)$ & $1.08^{\star \star \star}(0.15)$ & $2.08^{\star \star \star}(0.16)$ & $0.99^{\star \star \star}(0.15)$ \\
\hline $\begin{array}{l}\text { Limitations: } \\
\text { Respondent } \times \\
\text { Spouse }\end{array}$ & $0.01(0.01)$ & $0.01(0.01)$ & $0.02^{\star \star \star}(0.00)$ & $0.01^{\star \star}(0.00)$ \\
\hline \multicolumn{5}{|c|}{ Country dummies (Ref. Germany): } \\
\hline Austria & $0.82(0.56)$ & $-1.11^{\star \star \star}(0.31)$ & $-0.61(0.42)$ & $-0.96(0.49)$ \\
\hline Sweden & $-1.52(1.12)$ & $-0.74^{\star}(0.32)$ & $-0.79(0.46)$ & $-0.41(0.44)$ \\
\hline Spain & $1.56^{\star \star}(0.48)$ & $-1.29^{\star \star \star}(0.27)$ & $1.13^{\star \star \star}(0.32)$ & $0.16(0.29)$ \\
\hline Italy & $1.08 *(0.47)$ & $-1.71^{\star \star \star}(0.39)$ & $0.89^{\star \star}(0.32)$ & $0.07(0.32)$ \\
\hline France & $-0.33(0.59)$ & $-1.16^{\star \star \star}(0.31)$ & $-0.93(0.48)$ & $-0.99^{\star}(0.43)$ \\
\hline Denmark & $-0.64(0.73)$ & $-1.09^{\star \star}(0.38)$ & $-0.28(0.45)$ & $-0.90 *(0.46)$ \\
\hline Greece & $1.61^{\star \star}(0.47)$ & $-1.23^{\star \star \star}(0.32)$ & $0.91^{\star}(0.36)$ & $-0.92^{\star}(0.39)$ \\
\hline Switzerland & $-12.74(0.49)$ & $-0.94^{\star}(0.47)$ & $-0.49(0.48)$ & $0.29(0.43)$ \\
\hline Belgium & $0.24(0.54)$ & $-0.61^{\star}(0.27)$ & $-0.22(0.36)$ & $0.23(0.30)$ \\
\hline Czech Republic & $1.04^{\star}(0.44)$ & $-2.51^{\star \star \star}(0.40)$ & $-0.13(0.34)$ & $-1.42^{\star \star}(0.43)$ \\
\hline
\end{tabular}


Table 1. (Continued.)

\begin{tabular}{|c|c|c|c|c|}
\hline Solo care-giving versus & $\begin{array}{l}\text { Shared, } \\
\text { informally }\end{array}$ & $\begin{array}{l}\text { Shared, } \\
\text { formally }\end{array}$ & $\begin{array}{l}\text { Outsourced, } \\
\text { informally }\end{array}$ & $\begin{array}{l}\text { Outsourced, } \\
\text { formally }\end{array}$ \\
\hline Poland & $2.22^{\star \star \star}(0.55)$ & $-0.75(0.57)$ & $1.54^{\star \star}(0.57)$ & $0.49(0.53)$ \\
\hline Luxembourg & $0.77(0.74)$ & $0.33(0.45)$ & $-0.16(0.65)$ & $1.06^{\star}(0.46)$ \\
\hline Portugal & $-0.21(0.68)$ & $-1.45^{\star \star \star}(0.38)$ & $1.01^{*}(0.41)$ & $-0.76(0.49)$ \\
\hline Slovenia & $0.99(0.52)$ & $-2.49^{\star \star \star}(0.38)$ & $-0.08(0.47)$ & $-1.10^{\star \star}(0.42)$ \\
\hline Estonia & $0.80(0.46)$ & $-1.95^{\star \star \star}(0.37)$ & $-0.28(0.36)$ & $-1.43^{\star \star *}(0.39)$ \\
\hline Croatia & $0.82(0.61)$ & $-1.29^{\star}(0.57)$ & $0.96^{\star}(0.41)$ & $-2.09^{\star \star}(0.79)$ \\
\hline N (categories) & 341 & 425 & 660 & 408 \\
\hline N (total) & 4,012 & & & \\
\hline Pseudo- $R^{2}$ & 0.19 & & & \\
\hline Log-likelihood & $-4,241.72$ & & & \\
\hline
\end{tabular}

Notes: Multinomial logistic regressions with standard errors in parentheses. Respondents aged 50 years or older, living together with partner or spouse who has also answered questionnaire. Ref.: reference category.

Source: Survey of Health, Ageing and Retirement in Europe (SHARE) Release 6.0.0, Wave 6 (own calculations, unweighted results).

Significance levels: ${ }^{\star} p<0.05,{ }^{\star \star} p<0.01,{ }^{\star \star \star} p<0.001$.

socio-economic status is home-ownership (right panel of Figure 4). For homeowners, we find a significantly higher propensity to share care-giving formally, which is in line with our expectations (Hypothesis 3a). Living rent-free frees up financial resources, e.g. pension income, that can be spent on formal care-giving services without negatively impacting the household's standard of living. Owning living space might, moreover, allow hiring a live-in care-giver, who can be accommodated easier the larger the property.

Further factors influence the decision for solo versus shared care-giving. They include the age and functional health of both the respondent and his or her spouse and the help that is available from networks. Formally shared and formally outsourced care-giving occur more frequently when both spouses are old, and when the care-receiving spouse has many health limitations. Informally outsourced caregiving occurs more frequently the more daughters there are. When couples already receive IADL help from outside the household, there is a markedly higher propensity for sharing and outsourcing care.

\section{Multivariate findings: macro indicators}

As we have already seen in Figure 2, countries differ considerably in the distribution of care-giving arrangements. These country differences remain significant even when controlling for a range of relevant independent variables (see Table 1). We can thus assume that the mechanisms behind these differences are not (only) located at an individual level or due to 'composition effects', such as country variation in income, living conditions or health. Rather, the significant coefficients and 


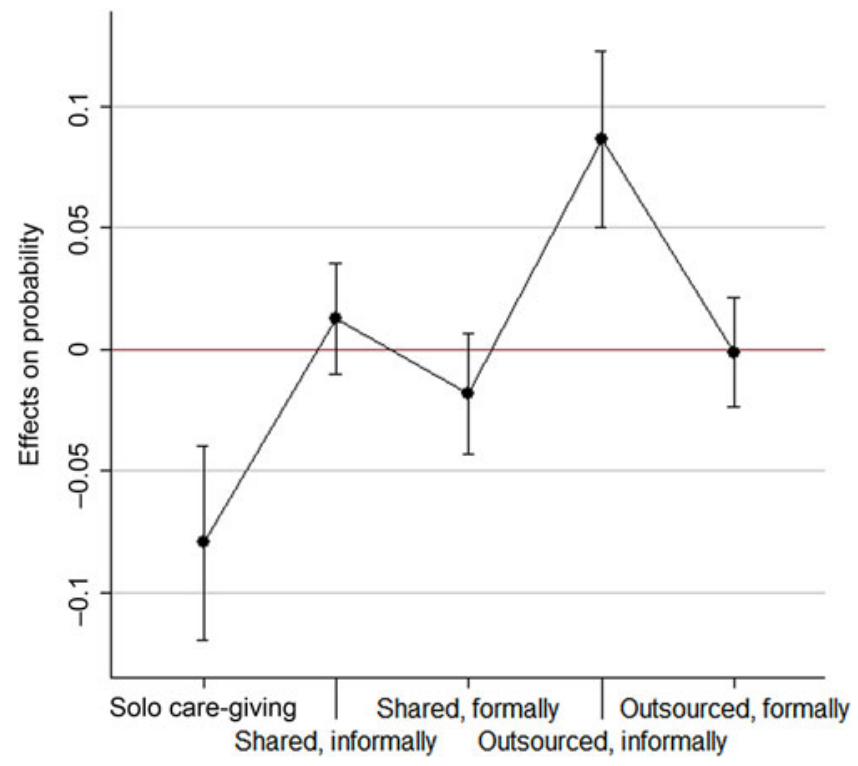

Figure 3. Average marginal effects of gender (male).

Notes: Capped spikes represent 95 per cent confidence intervals. Reference category: female. Calculations based on models from Table 1.

Source: Survey of Health, Ageing and Retirement in Europe (SHARE) Release 6.0.0, Wave 6.
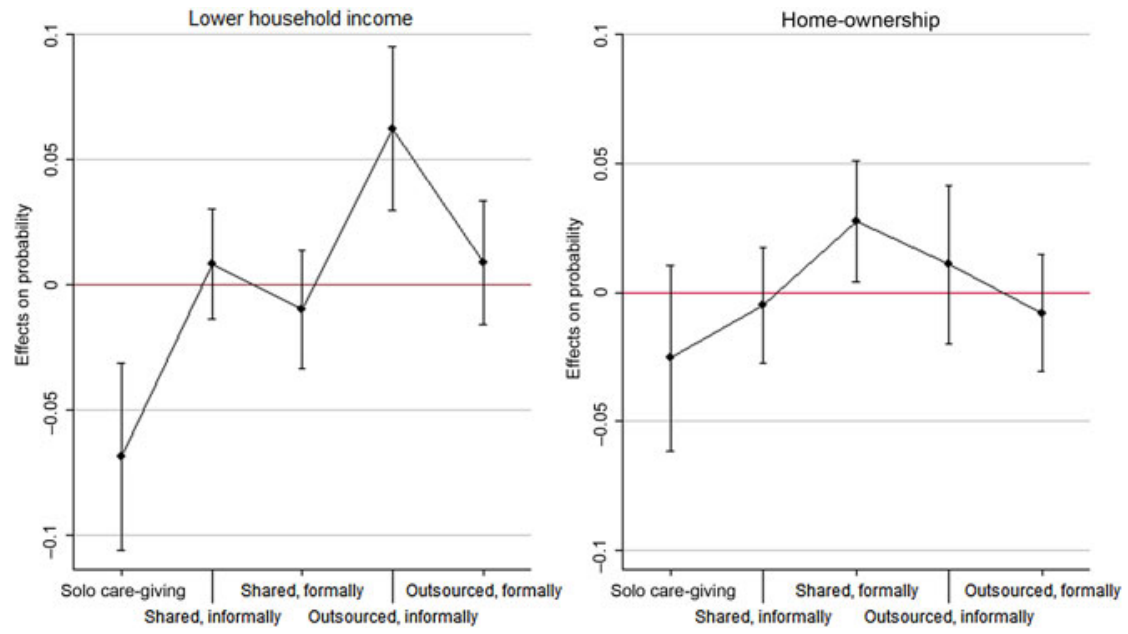

Figure 4. Average marginal effects of income and home-ownership.

Notes: Capped spikes represent 95 per cent confidence intervals. Calculations based on models from Table 1. Lower household income: first and second income quintile. $N=4,012$ individuals.

Source: Survey of Health, Ageing and Retirement in Europe (SHARE) Release 6.0.0, Wave 6. 
large effect sizes indicate that there are profound differences at the national level. We are interested in the link between public expenditures on two different eldercare schemes and the frequency of the occurrence of informally and formally shared and outsourced care-giving arrangements (see Figures 1 and 2 in the online supplementary material). We contrast two welfare state characteristics, namely Cash-for-Care and Care-in-Kind. Above-average expenditures for Care-in-Kind can be found in Sweden and Denmark. Above-average expenditures for Cashfor-Care are found in Italy, Greece, Portugal, Slovenia, France and Austria. In Luxembourg, Estonia and Switzerland, expenditures for both schemes are comparably low (for an overview, see Table 2 in the online supplementary material). In the next step, we therefore calculate our models including macro indicators containing information on the respective elder-care systems in each country (see Table 2).

Table 2 shows the effects of the macro indicators and their respective interaction terms with gender and socio-economic status introduced into the models of Table 1 (separate models for each interaction term). First, we look at the 'pure' effects without any interaction terms. Consistent with the respective policy goals, we find that Cash-for-Care schemes increase informally outsourced care-giving arrangements (a third person is paid to provide care). Contrary, the likelihood of sharing or outsourcing the care of one's spouse informally decreases when larger sums are committed to Care-in-Kind services, which is, too, in line with the associated policy goals such as unburdening non-resident family members, particularly children. However, the odds of choosing to share or outsource care formally over caring alone are not significantly higher in contexts with high expenditures on Care-in-Kind schemes. Care-in-Kind can thus be interpreted as an inclusive measure which does not 'crowd out' spouses as care-givers.

To test our fourth and fifth hypotheses, we estimated four separate models for each cross-level interaction. We assumed the influence of Care-in-Kind expenditures to be more gender-neutral, i.e. that men and women do not differ with respect to their choice of care-giving arrangements, than the influence of Cash-for-Care expenditures (Hypothesis 4). Moreover, we expected the effect of Care-in-Kind expenditures to be independent of individuals' socio-economic status (Hypothesis 5), while we expected the influence of Cash-for-Care expenditures to differ between individuals of lower and higher socio-economic status. As the interaction terms between gender and the macro indicators are not significant at the 0.05 level, this indicates that the effects of both schemes on the choice of care-giving arrangements mostly do not differ between men and women. This was expected for Care-in-Kind, albeit Cash-for-Care seems to be gender-neutral, too. At a first glance, this might contradict the findings by Schmid et al. (2012), where welfare state expenditures display gendered impacts on adult children's propensity to care for their parents. Spousal care-giving might, however, constitute an exception to this. As spousal care already features a relatively high share of male participation, it is plausible that care policies may reach out to care-giving husbands and wives in a comparable way.

With respect to differences between individuals of lower and higher socioeconomic status, a number of significant interaction terms indicate that these expenditures have a different impact on low-income and high-income households, as was expected from Hypothesis 5. To ease interpretation, we display predicted 
Table 2. Cross-level interactions: gender and socio-economic status

\begin{tabular}{|c|c|c|c|c|}
\hline & \multicolumn{4}{|c|}{ Solo versus } \\
\hline & $\begin{array}{l}\text { Shared, } \\
\text { informally }\end{array}$ & $\begin{array}{l}\text { Shared, } \\
\text { formally }\end{array}$ & $\begin{array}{l}\text { Out-sourced, } \\
\text { informally }\end{array}$ & $\begin{array}{l}\text { Out-sourced, } \\
\text { formally }\end{array}$ \\
\hline \multicolumn{5}{|l|}{ No interaction terms: } \\
\hline Cash-for-Care & $0.04(0.03)$ & $-0.03(0.03)$ & $0.09^{\star \star}(0.03)$ & $-0.01(0.03)$ \\
\hline Care-in-Kind & $-0.64^{\star \star \star}(0.18)$ & $0.12(0.11)$ & $-0.40^{\star \star}(0.14)$ & $-0.04(0.13)$ \\
\hline \multicolumn{5}{|l|}{ Gender interactions: } \\
\hline Cash-for-Care & $0.09^{*}(0.04)$ & $-0.04(0.04)$ & $0.07(0.04)$ & $-0.02(0.04)$ \\
\hline Male $\times$ Cash-for-Care & $-0.10(0.06)$ & $0.03(0.05)$ & $0.03(0.05)$ & $0.01(0.05)$ \\
\hline Care-in-Kind & $-0.45^{\star}(0.23)$ & $0.21(0.14)$ & $-0.41(0.23)$ & $0.09(0.19)$ \\
\hline Male $\times$ Care-in-Kind & $-0.39(0.34)$ & $-0.17(0.22)$ & $0.00(0.28)$ & $-0.27(0.23)$ \\
\hline \multicolumn{5}{|l|}{$\begin{array}{l}\text { Socio-economic status } \\
\text { interactions: }\end{array}$} \\
\hline Cash-for-Care & $0.05(0.04)$ & $0.05(0.03)$ & $0.04(0.03)$ & $0.08^{\star}(0.03)$ \\
\hline $\begin{array}{l}\text { Lower } \times \\
\text { Cash-for-Care }\end{array}$ & $-0.02(0.06)$ & $-0.21^{\star \star \star}(0.05)$ & $0.09(0.05)$ & $-0.24^{\star \star *}(0.06)$ \\
\hline Care-in-Kind & $-0.67^{\star}(0.27)$ & $0.14(0.16)$ & $-0.18(0.18)$ & $-0.10(0.18)$ \\
\hline Lower $\times$ Care-in-Kind & $0.07(0.35)$ & $-0.04(0.22)$ & $-0.44(0.26)$ & $0.06(0.25)$ \\
\hline
\end{tabular}

Notes: Multinomial logistic regression models with standard errors in parentheses. Respondents aged 50 years or older, living together with partner or spouse who has also answered questionnaire. $N=4,012$ in 17 countries. Separate models for each indicator and interaction, controlling for individual-level variables from Table 1. Pseudo- $R^{2}=0.14$.

Source: Survey of Health, Ageing and Retirement in Europe (SHARE), Release 6.0.0, Wave 6; Organisation for Economic Co-operation and Development (2017) (own calculations, unweighted results).

Significance levels: ${ }^{*} p<0.05,{ }^{* *} p<0.01,{ }^{* * *} p<0.001$.

probabilities for sharing informally and formally (see Figure 5). In higher-income households, increased cash allowances for care-givers do not lead to higher rates of sharing care formally. In contrast, the likelihood of spending the cash allowances received on formal care (either through sharing or through outsourcing) is significantly lower for households with low income (top right panel). Care-in-Kind, as expected, does not seem to impact differently on lower- and higher-income households (lower panels). With regard to outsourcing care, higher Cash-for-Care expenditures are associated with a higher probability of wealthier households outsourcing care formally (see Figure 3 in the online supplementary material). Together with the findings pertaining to sharing care, this indicates that there are indeed differences between higher and lower socio-economic groups regarding the impact of welfare policy on the choice of a care-giving arrangement.

\section{Discussion}

Our results show that care-giving within the marital dyad today is still a popular and widely used option for dealing with declining health within a partnership. Of those individuals aged 50 years or older living together with a spouse who receives care, 

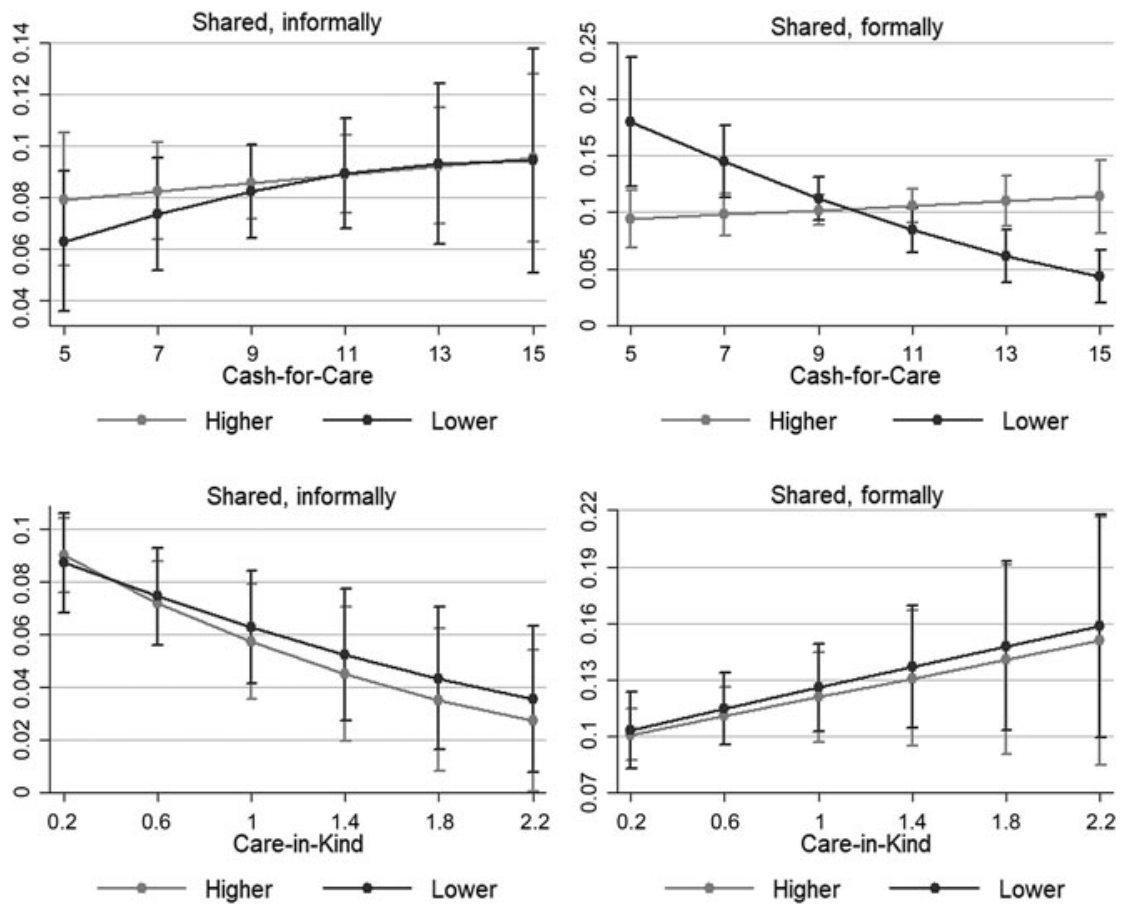

Figure 5. Predicted probabilities of shared care-giving arrangements over Cash-for-Care and Care-in-Kind policies, by household income.

Notes: Capped spikes represent 95 per cent confidence intervals. The $x$-axis indicates the percentage of expenditure for the respective scheme as a share of total Gross Domestic Product; the $y$-axis indicates the prevalence of the caregiving arrangement. Calculations are based on separate models with cross-level interactions from Table 2. Lower household income: first and second income quintile; higher household income: third to fifth income quintile. $\mathrm{N}=$ 4,012 individuals.

Source: Survey of Health, Ageing and Retirement in Europe (SHARE), Release 6.0.0, Wave 6; Organisation for Economic Co-operation and Development (2017).

around 80 per cent are themselves engaged in spousal care-giving, and around half act as solo care-givers. However, exclusive long-term spousal care-giving is neither the only option nor the last resort. As couples age together, it is often the functionally less-limited person who provides care for the functionally more limited one. With growing care demands, taking care of a frail spouse alone may become difficult. When the care load is intense, and a care-giver's health is impaired, the care load is likely to become shared with informal or formal helpers or outsourced completely to a third person. Besides health, our results indicate that there is a range of other factors involved in the choice of care-giving arrangements, which makes it necessary to differentiate between spousal care-givers further. Spousal care can be split into solo or shared care-giving, and - in the case of shared care - whether care is shared with informal or formal helpers. Deciding on a care-giving arrangement is thus a complex problem which depends on various dimensions of needs and resources of several actors, as well as on family and social contexts. 
In many European countries, men are relatively often involved in spousal caregiving, although women are more often involved, and more likely to be the solo care-giver. However, the circumstances that determine whether men choose solo or shared ADL care-giving have not been subject to systematic comparative research based on representative data. The present article thus contributes in several respects: our comparative analyses confirm that, contrary to many other fields of care-giving, men are substantially involved in spousal care-giving. However, men and women seem to choose different care-giving arrangements. While most caregiving women act as solo care-givers, men share care-giving with informal helpers significantly more often, i.e. with family members, friends or neighbours. In that respect, our findings are in line with previous literature. Men's choice of informally shared care-giving can partly be explained by their higher propensity to be engaged in the labour market. As employment and care-giving compete for time resources, we argue that informally shared care-giving arrangements offer more flexibility to combine work and care-giving than formally shared care-giving arrangements. Financial resources, on the other hand, seem to be less important than time resources. Moreover, the results depend on which indicator for financial resources is considered. While income only plays a marginal role in determining the caregiving arrangement, home-ownership proves to be a financial asset which allows for the purchasing of formal services.

Besides individual characteristics, welfare policy in the respective country plays an important role, too. We compare expenditures for two public policy schemes. Care-in-Kind measures constitute inclusive measures when it comes to the engagement of spouses as care-givers, but they do, as expected, 'crowd out' other informal helpers, presumably own children (Brandt et al., 2009). However, even with rising expenditures on Care-in-Kind schemes, the odds of using formally shared caregiving as compared to solo care-giving are not significantly higher. Even in contexts with high public expenditures on home care services, most elderly couples seem to rely exclusively on spousal care. This effect is largely driven by Sweden and Denmark which might look astonishing at first glance but is in line with previous literature. Despite its orientation towards formal care, in Denmark, it is legally possible to choose a private person as a paid care-giver, who thereupon enters a formal employment contract with the municipality (Frericks et al., 2014). In Sweden, home help is more widely used than home care (Jegermalm, 2006; Lagergren et al., 2012). What is more, public expenditures for elder-care in Sweden have seen a marked decline since the 1990s, paralleled by a growing marketisation of the care infrastructure (Savla et al., 2008; Szebehely and Trydegard, 2012). A comparatively high expenditure on home services might also reflect an increased volume of publicly funded but market-provided IADL services, the use of which has not been the focus of this article.

Cash-for-Care schemes, on the other hand, mean 'extra cash' in the household budget of the frail person and his or her spouse. Higher expenditures on Cash-for-Care schemes increase the odds of informally shared care-giving and informal outsourcing to a third care-giver. The use of such 'extra cash', though, was shown to vary with socio-economic status: the more 'extra cash' is available, the higher the propensity of higher-income households to spend it on formal home care, and the higher the propensity of lower-income households to choose 
informally shared care-giving arrangements. Households with a higher socioeconomic status can complement cash allowances with their own means to engage a formal care-giver, while lower-income households tend to keep the 'extra cash' within their personal networks through engaging informal helpers. With increasing expenditures on Cash-for-Care, we can thus observe a diverging trend in the usage of the allowances between households of different socio-economic status. Care-inKind, on the other hand, seems to constitute a rather inclusive measure. While households with lower and higher socio-economic status do not differ in their choice of shared care-giving arrangements or formal outsourcing in contexts with high expenditures on formal home care services, the gap between higher and lower socio-economic status households is significantly narrowed with respect to informally outsourced care-giving.

\section{Limitations and research agenda}

The focus on the various care-giving arrangements of spousal ADL care is a strength and limitation of the present article at the same time. Drawing on previous literature that clearly distinguishes between help and care, we would like to point out that our findings are only partially applicable to the provision of IADL help, as ADL and IADL support might follow different paths. Future research could thus elaborate an array of more detailed care-giving arrangements which includes sharing and outsourcing as well as informal and formal helpers, considering $\mathrm{ADL}$ and IADL as two distinct support types. Moreover, our research question motivated the analysis of couples living in the same household. This results in the limitation that we might have a selection bias towards couples where the care-receiving spouse is not capable of participating in the survey. To minimise such bias, we control for spouse's age and number of functional health limitations.

Furthermore, our models are based on cross-sectional data. Our analyses depend on detailed information to preclude confusion of IADL and ADL care-giving and to distinguish between informal and formal helpers. For the results presented in the article, we thus relied on Wave 6 of SHARE exclusively, which might result in problems with endogeneity. However, to test for robustness, we calculated fixed-effects logistic models with the occurrence of spousal care-giving in the respective wave as a dichotomous dependent variable (see Table 3 in the online supplementary material). As these models suggest, most coefficients (e.g. gender, both partners' age and health, gender and residential distance of children) point in the same direction, apart from the coefficients for home-ownership and employment. Home-ownership displays a negative effect on the overall likelihood of engaging in care-giving in the longitudinal model but a positive effect on formal sharing in the crosssectional model. As newly purchasing a home in older age is rather unlikely, the longitudinal effect supposedly stems from older couples moving out of their owned home. The finding suggests that individuals who give up their owned home are more likely to start caring for their spouse. Changes in housing and caregiving arrangements are both likely to be linked to changes in health. However, while the coefficients in the longitudinal models describe the propensity to switch from non-care-giving (including cases where the spouse does not need care) to 
care-giving, the cross-sectional models compare solo care-givers with four other care-giving arrangements. The positive cross-sectional effect might also capture differences between the more fine-grained options of care-giving arrangements. Future research should thus, given the existence of a suitable data basis, also address switching between various care-giving arrangements in a longitudinal perspective.

Moreover, employment displays no effect in the longitudinal models and a positive effect on outsourcing and informal sharing in the cross-sectional models. Again, there are two plausible explanations: first, the cross-sectional effect might capture time-invariant individual characteristics, such as individual labour market orientation, which are held constant in the fixed-effects model. Second, the various care-giving arrangements might differ in their compatibility with employment, as we have seen that employees choose informal over formal sharing. Here, too, the binary measure of care-giving in the longitudinal models (see above) might account for the differences between the models. Generally, our article shows the importance of investigating spousal care as a specific form of informal care-giving. To sum up, we conclude that there is large variation in care-giving arrangements chosen by spousal care-givers. The choice of such care-giving arrangements depends on sex, socio-economic status and welfare policy context. Moreover, by contrasting Cash-for-Care and Care-in-Kind expenditures, we were able to show that the impact of policy measures for long-term care on care-giving arrangements varies with socio-economic status and may, thereby, contribute to both reducing or preserving inequalities in old age.

\section{Notes}

1 The present paper investigates care-giving occurring in married and unmarried co-habiting couples. For the sake of readability, both forms of partnership and the respective care provided are referred to as 'spouses' and 'spousal care', respectively.

2 Multiple observations per household are possible when both spouses either provide and/or receive care.

Supplementary material. The supplementary material for this article can be found at https://doi.org/10. 1017/S0144686X18001320

Data. This paper uses data from SHARE Wave 6 (DOIs: 10.6103/SHARE.w6.600). The SHARE data collection has been primarily funded by the European Commission through FP5 (QLK6-CT-2001-00360), FP6 (SHARE-I3: RII-CT-2006-062193, COMPARE: CIT5-CT-2005-028857, SHARELIFE: CIT4-CT-2006028812) and FP7 (SHARE-PREP: No. 211909, SHARE-LEAP: No. 227822, SHARE M4: No. 261982). Additional funding from the German Ministry of Education and Research, the Max Planck Society for the Advancement of Science, the US National Institute on Aging (U01_AG09740-13S2, P01_AG005842, P01_AG08291, P30_AG12815, R21_AG025169, Y1-AG-4553-01, IAG_BSR06-11, OGHA_04-064, HHSN271201300071C) and from various national funding sources is gratefully acknowledged (see www. share-project.org).

Acknowledgements. The authors would like to thank the two anonymous referees for their helpful comments and feedback. The authors are further indebted to Klaus Preisner and Ronny König for their comments on an earlier draft of the manuscript. We also benefited from feedback after giving presentations in Konstanz, Bern and Seoul.

Financial support. This work was supported by the German Research Foundation (DFG) (project number STR1322/2-10). 


\section{References}

Alber J and Kohler U (2004) Health and Care in an Enlarged Europe. Dublin: European Foundation for the Improvement of Living and Working Conditions.

Andersen R and Newman JF (1973) Societal and individual determinants of medical care utilization in the United States. The Milbank Memorial Fund Quarterly. Health and Society 51, 95-124.

Arber S and Ginn J (1992) Class and caring: a forgotten dimension. Sociology 26, 619-634.

Arber S and Ginn J (1994) Gender differences in informal caring. Health \& Social Care in the Community 3, 19-31.

Balia S and Brau R (2014) A country for old men? Long-term home care utilization in Europe. Health Economics 23, 1185-1212.

Becker GS (1965) A theory of the allocation of time. The Economic Journal 75, 493-517.

Bettio F and Plantenga J (2004) Comparing care regimes in Europe. Feminist Economics 10, 85-113.

Blomgren J, Breeze E, Koskinen S and Martikainen P (2011) Help from spouse and from children among older people with functional limitations: comparison of England and Finland. Ageing \& Society 32, 905-933.

Bond J, Farrow G, Gregson B, Bamford C, Buck D, McNamee P and Wright K (1999) Informal caregiving for frail older people at home and in long-term care institutions: who are the key supporters? Health \& Social Care in the Community 7, 434-444.

Börsch-Supan A (2017) Survey of Health, Ageing and Retirement in Europe (SHARE) Wave 6. Release version: 6.0.0. SHARE-ERIC. Data set. doi:10.6103/SHARE.w6.611.

Brandt M, Haberkern K and Szydlik M (2009) Intergenerational help and care in Europe. European Sociological Review 25, 585-601.

Broese van Groenou M, Glaser K, Tomassini C and Jacobs T (2006) Socio-economic status differences in older people's use of informal and formal help: a comparison of four European countries. Ageing \& Society 26, 745-766.

Connidis IA and McMullin JA (2002) Sociological ambivalence and family ties: a critical perspective. Journal of Marriage and Family 64, 558-567.

Corden A and Hirst M (2011) Partner care at the end-of-life: identity, language and characteristics. Ageing \& Society 31, 217-242.

Deufert D (2013) Genderaspekte in der Angehörigenpflege. Zeitschrift für Gerontologie und Geriatrie 46, 520-525.

Dwyer JD and Seccombe K (1991) Elder care as family labor. Journal of Family Issues 12, 229-247.

Ettner SL (1996) The opportunity costs of elder care. Journal of Human Resources 31, 189-205.

Eurostat (2017) Mortality and Life Expectancy Statistics. Available at http://ec.europa.eu/eurostat/statisticsexplained/index.php/Mortality_and_life_expectancy_statistics.

Feld S, Dunkle RE, Schroepfer T and Shen H-W (2010) Does gender moderate factors associated with whether spouses are the sole providers of IADL care to their partners? Research on Aging 32, 499-526.

Frericks P, Jensen PH and Pfau-Effinger B (2014) Social rights and employment rights related to family care: family care regimes in Europe. Journal of Aging Studies 29, 66-77.

Gallo E and Scrinzi F (2016) Outsourcing elderly care to migrant workers: the impact of gender and class on the experience of male employers. Sociology 50, 366-382.

Gerstel N and Gallagher S (2001) Men's caregiving. Gender and the contingent character of care. Gender \& Society 15, 197-217.

Haberkern K and Szydlik M (2010) State care provision, societal opinion and children's care of older parents in 11 European countries. Ageing \& Society 30, 299-323.

Hank K (2011) Societal determinants of productive aging: a multilevel analysis across 11 European countries. European Sociological Review 27, 526-541.

Henz U (2009) Couples' provision of informal care for parents and parents-in-law: far from sharing equally? Ageing \& Society 29, 369-395.

Henz U (2010) Parent care as unpaid family labor: how do spouses share? Journal of Marriage and Family 72, 148-164.

Hirst M (2001) Trends in informal care in Great Britain during the 1990s. Health and Social Care in the Community 9, 348-357. 
Hong S-C and Coogle CL (2016) Spousal caregiving for partners with dementia: a deductive literature review testing Calasanti's gendered view of care work. Journal of Applied Gerontology 35, 759-787.

Jegermalm M (2006) Informal care in Sweden: a typology of care and caregivers. International Journal of Social Welfare 15, 332-343.

Lagergren M, Sjölund B-M, Fagerström C, Berglund J, Fratiglioni L, Nordell E, Wimo A and Elmståhl S (2012) Horizontal and vertical target efficiency - a comparison between users and non-users of public long-term care in Sweden. Ageing \& Society 34, 700-719.

McAuley W and Arling G (1984) Use of in-home care by very old people. Journal of Health and Social Behavior 25, 54-64.

Messeri P, Silverstein M and Litwak E (1993) Choosing optimal support groups: a review and reformulation. Journal of Health and Social Behavior 34, 122-137.

Motel-Klingebiel A, Tesch-Römer C and von Kondratowitz H-J (2005) Welfare states do not crowd out the family: evidence for mixed responsibility from comparative analyses. Ageing \& Society 25, 863-882.

Mutchler JE and Bullers S (1994) Gender differences in formal care use in later life. Research on Aging 16, 235-250.

Noël-Miller CM (2011) Partner caregiving in older cohabiting couples. Journals of Gerontology 66, 341-353.

Organisation for Economic Co-operation and Development (OECD) (2017) Public expenditure on oldage and survivors cash benefits, in \% GDP. Retrieved from: www.stats.oecd.org, 21.08.2017.

Orloff A (1996) Gender in the welfare state. Annual Review of Sociology 22, 51-78.

Pfau-Effinger B (2005) Welfare state policies and the development of care arrangements. European Societies 7, 321-347.

Pickard L, Wittenberg R, Comas-Herrera A, King D and Malley J (2007) Care by spouses, care by children: projections of informal care for older people in England to 2031. Social Policy \& Society 6, 353-366.

Ribeiro O and Paul C (2008) Older male carers and the positive aspects of care. Ageing \& Society 28, 165-183.

Russell R (2007) Men doing 'women's work:' elderly men caregivers and the gendered construction of care work. Journal of Men's Studies 15, 1-18.

Saraceno C and Keck W (2010) Can we identify intergenerational policy regimes in Europe? European Societies 12, 675-696.

Sarkisian N and Gerstel N (2004) Explaining the gender gap in help to parents: the importance of employment. Journal of Marriage and Family 66, 431-451.

Savla J, Davey A, Sundström G, Zarit SH and Malmberg B (2008) Home help services in Sweden: responsiveness to changing demographics and needs. European Journal of Ageing 5, 47-55.

Schmid T, Brandt M and Haberkern K (2012) Gendered support to older parents: do welfare states matter? European Journal of Ageing 9, 39-50.

Shen H-W, Feld S, Dunkle RE, Schroepfer T and Lehning A (2015) The prevalence of older couples with ADL limitations and factors associated with ADL help receipt. Journal of Gerontological Social Work 58, 171-189.

Strauss S and Trommer K (2017) Productive ageing regimes in Europe: welfare state typologies explaining elderly Europeans' participation in paid and unpaid work. Journal of Population Ageing. online first doi:10.1007/s12062-017-9184-4.

Suanet B, Broese van Groenou M and Van Tilburg T (2012) Informal and formal home-care use among older adults in Europe: can cross-national differences be explained by societal context and composition. Ageing \& Society 32, 491-515.

Szebehely M and Trydegard G-B (2012) Home care for older people in Sweden: a universal model in transition. Health and Social Care in the Community 20, 300-309.

Walker AJ, Pratt CC and Eddy L (1995) Informal caregiving to aging family members: a critical review. Family Relations 44, 401-411.

Cite this article: Bertogg A, Strauss S (2020). Spousal care-giving arrangements in Europe. The role of gender, socio-economic status and the welfare state. Ageing \& Society 40, 735-758. https://doi.org/10.1017/ S0144686X18001320 